\title{
Editorial
}

\section{Heart failure - How can we face this pandemic of twenty first century?}

\author{
STM Abu Azam¹, Mohammad Ullah²
}

(Bangladesh Heart Journal 2016; 31(1) : 1-2)

Heart failure is now in the form of a pandemic across the world and a serious threat to the heath and financial wellbeing of people. It affects approximately $6 \%$ of people aged between 60 and 86 years. ${ }^{1}$ The incidence of heart failure increases twofold for each decade of life. ${ }^{2}$ Personal, economic and health care burden of heart failure is expected to increase more in the future as life expectancy of people increases, placing further pressure on the finite health care resources.

Previously it was thought to be a problem of the people of developed world; and developing world was busy with communicable and nutritional diseases. Now along with decrease in communicable diseases in countries like Bangladesh, prevention and management of non communicable diseases have become the main concern. Almost all the non communicable diseases like, hypertension, diabetes mellitus, ischaemic heart disease, chronic kidney disease etc. end up in heart failure. Besides this, improved management of acute coronary syndrome and improved longevity of the population have also contributed to the increased magnitude of heart failure burden.

In USA $1.9 \%$ of the total population suffer from heart failure. There is no such data for Bangladesh. But Asian countries like Japan \& China have got an incidence of $1 \%$ and $1.3 \%$ respectively. Overall, the prevalence of heart failure in Asia is $1.26 \%$ to $6.7 \% .^{3}$ In Bangladesh, rheumatic heart disease still plays an important role in the incidence of heart failure, complicating the scenario. In a study conducted in National Institute of Cardiovascular Diseases and different medical colleges of Bangladesh revealed that IHD was responsible for $65 \%$ of chronic heart failure, rheumatic heart disease for $18 \%$ cases, hypertension for $12 \%$ cases and idiopathic cardiomyopathy for $5 \%$ cases. ${ }^{4}$ The average age of Asian

1. Director and Professor, National Institute of Cardiovascular Diseases, Dhaka.

2. Assistant Professor, Dept. of Cardiology, National Institute of Cardiovascular Diseases, Dhaka. population suffering from heart failure is 10 years lesser than that of western population. So its economic impact is also higher. ${ }^{5}$

Are we prepared to face this new monster of twenty first century? The answer is -'No'. We have got no data regarding the magnitude of the heart failure. We must conduct study to get enough information, so that we can make out a strategy to manage the problem. The management of heart failure should be a multidisciplinary one, which will involve cardiologists, internists, respiratory physician, paramedics, nurses, nutritionists and social workers. It can be provided only by a 'heart failure clinic', like diabetes care centers. We should try to develop 'heart failure clinics' at least in all the tertiary care hospitals and regional hospitals.

To control the pandemic we must increase the awareness of the people about the risk and impact of the heart failure. We must concentrate on prevention of heart failure by providing better treatment of hypertension, diabetes mellitus, ischaemic heart disease, obesity and other risk factors which predispose to heart failure. The treatment of Stage $C$ heart failure should be more organized and more optimized. Most of the patients of heart failure do not receive adequate follow up treatment after they are discharged from hospital. This is due to lack of adequate motivation and lack of heart failure clinics. This results in lack of understanding of a treatment plan, non adherence to medical therapy and unawareness of heart failure symptom exacerbation. But early follow up visit within one week can lead to $8 \%$ and $29 \%$ risk reduction of all cause readmission and emergency department visits. ${ }^{6}$

Many guideline directed medications are not prescribed or prescribed at a lower dose, which needs addition and optimization in follow up visits. Only a regular follow up visit by a dedicated group of people in a heart failure clinic can make it possible. Sometimes it can be titrated by trained nurses and paramedics under supervision of a heart failure specialist. Cochrane data base review 
reveals that 27 deaths can be avoided in every 1000 patients undergoing titration of the mediation by nurses under medical supervision. ${ }^{7}$

Drug related problems are also a common one in heart failure patients under treatment. A probability model has been used to estimate the drug related problems in heart failure patients in USA. Drug related problems are responsible for $\$ 76.6$ billion in hospital costs, 17 million emergency department visits and 8.7 million admissions annually. ${ }^{8}$ The majority of hospital admissions and emergency department visits are preventable, and an effective medication review for the successful detection of drug related problems remains an unmet clinical need, and it can only be done by patient education and regular follow up in a heart failure clinic. ${ }^{9}$

Heart failure clinics should provide services through multidisciplinary approach. They should give the pharmacological treatment as well as advice for life style modification regarding diet, exercise, smoking, substance abuse, sleep, travelling, sexual activity, adherence to drug therapy, symptoms monitoring, self care etc. Cardiac rehabilitation and palliative care may be integrated into the overall provision for patients with heart failure.

Expertise and facilities for treatment of Stage $D$ heart failure should also be improved, though it is a costly one. But most of these treatments have already been proved to be cost effective in many countries. Different devices for the treatment of heart failure like implantable cardioverter defibrillator, cardiac resynchronization therapy, left ventricular assist device should be made available for the patients who can afford it. We must improve our facilities for implantation of these devices; and our skill and knowledge for implantation and maintenance of these devices should also be improved. Heart transplantation is another option for the patients with resistant heart failure. Like many of the developing countries, Bangladesh is far behind the goal regarding this. Our cardiologists, cardiac surgeons, policy makers, other related persons should think about it.

Heart failure will be most prevalent and important cardiovascular illness we have to face in coming decades. We are not still prepared enough to face this pandemic of twenty first century. We need a coordinated service of the related services within the healthcare system. This needs close collaboration between heart failure practitioners and experts in allied health professions, including nurses, paramedics, dieticians, physiotherapists, psychologists, primary care providers, and social workers. 'Heart failure clinics' can bring all these services altogether to the patients.

\section{References:}

1. Guo Y, Lip GY, Banerjee A. Heart failure in East Asia. Curr Cardiol Rev 2013;9:112-122.

2. Go AS, Mozaffarian D, Roger VL, Benjamin EJ, Berry JD, Borden WB, et al. Heart disease and stroke statistics 2013 update: a report from the American Heart Association. Circulation 2013;127:e6-245.

3. Sakata Y, Shimokawa H. Epidemiology of heart failure in Asia. Circ J 2013;77:2209-2217.

4. Majumder AAS, Rahman MT, Islam MS, Farid N, Gafur S, Rahman MA, Bari MS, Kabir MS, Islam AEMM, Ullah M. Aetiological Diagnosis of Heart Failure in Hospitalized Patients. Cardiovascular Journal 2009; 2(1) : 32-36.

5. Atherton JJ, Hayward CS, Wan Ahmad WA, et al. Patient characteristics from a regional multicenter database of acute decompensated heart failure in Asia Pacific (ADHERE International-Asia Pacific). J Card Fail 2012;18: 82-88.

6. Vedel I, Khanassov V. Transitional Care for Patients with Congestive Heart Failure: A Systematic Review and Meta-Analysis. Ann Fam Med 2015;13: 562-571.

7. Driscoll A, Currey J, Tonkin A, KrumH. Nurse-led titration of angiotensin converting enzyme inhibitors, beta-adrenergic blocking agents, and angiotensin receptor blockers for people with heart failure with reduced ejection fraction. Cochrane Database Syst Rev 2015, Issue 12. Art. No.: CD009889.

8. Johnson JA, Bootman JL. Drug-related morbidity and mortality. A cost-of-illness model. Arch Intern Med 1995;155:1949-1956.

9. Hsu WT, Shen LJ, Lee CM. Drug-related problems vary with medication category and treatment duration in Taiwanese heart failure outpatients receiving case management. J Formos Med Assoc 2015; xx: 1-8. 